\title{
Prognostic value of a novel FPR biomarker in patients with surgical stage II and III gastric cancer
}

\author{
Jing Zhang ${ }^{1, *}$, Shu-Qi Li, ${ }^{1, *}$, Zhi-Hua Liao ${ }^{2, *}$, Yu-Huan Jiang ${ }^{1}$, Qing-Gen Chen ${ }^{1}$, Bo \\ Huang ${ }^{1}$, Jing Liu ${ }^{1}$, Yan-Mei X ${ }^{1}{ }^{1}$, Jin Lin ${ }^{1}$, Hou-Qun Ying ${ }^{1}$ and Xiao-Zhong Wang ${ }^{1}$ \\ ${ }^{1}$ Jiangxi Province Key Laboratory of Laboratory Medicine, Department of Clinical Laboratory, The Second Affiliated Hospital \\ of Nanchang University, Nanchang, 330006, China \\ ${ }^{2}$ Department of Clinical Laboratory, Jiangxi Provincial Maternal and Child Health Hospital, Nanchang, 330006, China \\ *Authors contributed equally to this work \\ Correspondence to: Xiao-Zhong Wang, email: wangxiaozhong@ncu.edu.cn \\ Hou-Qun Ying, email: yinghouqun2013@163.com \\ Keywords: inflammation, gastric cancer, prognosis, nomogram
}

Received: March 07, $2017 \quad$ Accepted: July 25, $2017 \quad$ Published: September 06, 2017

Copyright: Zhang et al. This is an open-access article distributed under the terms of the Creative Commons Attribution License 3.0 (CC BY 3.0), which permits unrestricted use, distribution, and reproduction in any medium, provided the original author and source are credited.

\section{ABSTRACT}

Background: Inflammation and nutrition are two main causes contributing to progression of gastric cancer (GC), and inflammatory biomarker may be presented as its valuable prognostic factor. Thus, this study was carried out to investigate the prognostic significance of preoperative circulating albumin/fibrinogen ratio (AFR), fibrinogen/pre-Albumin ratio (FPR), fibrinogen (Fib), albumin (Alb) and pre-Albumin (pAlb) in surgical GC.

Materials and Methods: Three hundred and sixty surgical stage II and III GC patients from June 2011 to December 2013 were enrolled in this retrospective study. $X$-tile software, Kaplan-Meier curve and Cox regression model were used to evaluate the prognostic role of them. A predictive nomogram was established to predict prognosis of overall survival (OS), and its accuracy was assessed by concordance index (c-index).

Results: Decreased Alb, pAlb, AFR and elevated FPR were significantly associated with shorter OS. FPR was identified as the most effective prognostic factor to predict 3-year's OS by time-dependent ROC analysis. A long survival was observed in patients with low level of FPR and the prognosis of stage III FPR-low GC patients undergoing chemotherapy was significantly superior to the patients without the treatment $(P=0.002)$. However, no difference of survival was examined in stage II subgroups stratified by FPR and high FRP of stage III patients with or not the treatment of chemotherapy. C-index of nomogram containing FPR (c-index $=0.756$ ) was high in comparison with the nomogram without FPR (c-index $=0.748$ ).

Conclusion: Preoperative FPR might be a feasible prognostic biomarker in surgical stage II and III GC and it could precisely distinguish stage III patients who appeared to obviously benefit from adjuvant chemotherapy. Meanwhile established nomogram based on clinical parameters and FPR could improve its predictive efficacy.

\section{INTRODUCTION}

Gastric cancer (GC), one of the most common malignancies, is the second most cause of mortality worldwide [1]. Although rapid improvement of surgery and adjuvant treatment in past decade, the prognosis of GC patients remained unsatisfactory owing to recurrence or metastasis after curative resection [2]. Therefore, promising prognostic biomarker which predicted its 
Table 1: Clinical and pathological characteristics in 360 gastric cancer patients

\begin{tabular}{|c|c|c|}
\hline Variables & Categories & Total patients $(n=360)$ \\
\hline & & No. of patients (\%) \\
\hline \multirow[t]{2}{*}{ Gender } & Male & $261(72.5)$ \\
\hline & Female & $99(27.5)$ \\
\hline Age & year & $58.24 \pm 11.22$ \\
\hline \multirow[t]{2}{*}{ Tobacco } & Yes & $120(33.3)$ \\
\hline & No & $240(66.7)$ \\
\hline \multirow[t]{2}{*}{ Alcohol } & Yes & $82(22.8)$ \\
\hline & No & $278(77.2)$ \\
\hline \multirow[t]{2}{*}{ Hypertension } & Yes & $44(12.2)$ \\
\hline & No & $316(87.8)$ \\
\hline \multirow[t]{2}{*}{ Diabetes } & Yes & $17(4.7)$ \\
\hline & No & $343(95.3)$ \\
\hline \multirow[t]{2}{*}{ Adjuvant Chemotherapy } & Yes & $249(69.2)$ \\
\hline & No & $111(30.8)$ \\
\hline \multirow[t]{2}{*}{ Differentiation } & well & $159(44.2)$ \\
\hline & poor & $201(55.8)$ \\
\hline \multirow[t]{2}{*}{ Tumor stage } & II & $123(34.2)$ \\
\hline & III & $237(65.8)$ \\
\hline \multirow[t]{2}{*}{ Depth of invasion } & $\mathrm{T} 1-\mathrm{T} 2$ & $86(23.9)$ \\
\hline & $\mathrm{T} 3-\mathrm{T} 4$ & $274(76.1)$ \\
\hline \multirow[t]{2}{*}{ Lymph node } & N0 & $134(37.2)$ \\
\hline & N1-N3 & $226(62.8)$ \\
\hline \multirow[t]{2}{*}{ Tumor size } & $\leq 5 \mathrm{~cm}$ & $272(75.6)$ \\
\hline & $>5 \mathrm{~cm}$ & $88(24.4)$ \\
\hline Fib & $\mathrm{mg} / \mathrm{dl}$ & $3.31(0.93-6.27)$ \\
\hline Alb & $\mathrm{g} / 1$ & $38.79(26.21-49.57)$ \\
\hline pAlb & $\mathrm{mg} / 1$ & $214.15(67.3-437.9)$ \\
\hline FPR & & $17.97(3.03-83.47)$ \\
\hline AFR & & $12.96(5.76-43.26)$ \\
\hline \multirow[t]{2}{*}{ CEA } & $\leq 5 \mathrm{ng} / \mathrm{ml}$ & $309(85.8)$ \\
\hline & $>5 \mathrm{ng} / \mathrm{ml}$ & $51(14.2)$ \\
\hline \multirow[t]{3}{*}{ CA199 } & $\leq 37 \mathrm{U} / \mathrm{ml}$ & $303(84.2)$ \\
\hline & $>37 \mathrm{U} / \mathrm{ml}$ & $55(15.3)$ \\
\hline & NA & $2(0.5 \%)$ \\
\hline 3 years' OS & month & 36 \\
\hline
\end{tabular}

Abbreviation: NA: not available; Fib: fibrinogen; Alb: albumin; pAlb: pre-Albumin; AFR: albumin/fibrinogen ratio; FPR: fibrinogen/pre-Albumin ratio (FPR); CEA: carcinoembryonic antigen; FAS: FPR and Alb Score; mFAS: modified FPR and Alb Score; OS: overall survival;

progression and survival would be helpful for management and treatment in these patients.

It has been well known that inflammation and nutrition are closely associated with progression and survival of GC [3-5]. Anti-inflammatory treatment and nutritional care could prevent cancer progression and improve prognosis of the patients [5-7]. Seo et al. reported that preoperative adequate albumin (Alb) and energy intake could improve therapeutic effect of the patients [5]. Kim et al. demonstrated that long-term low-dose aspirin intake could reduce susceptibility to GC [7]. Circulating nutritional and inflammatory mediators such as fibrinogen(Fib), Alb and pre-albumin(pAlb) are usually aberrant in these patients. Emerging evidences indicated that high level of plasma Fib were significantly associated with poor clinical outcome of GC patients [8-10], and preoperative low serum pAlb level and hypoalbuminemia were considered to be predictors for shorter overall survival (OS) in GC patients $[11,12]$. A recent study reported that circulating albumin to gamma-glutamyltransferase ratio could apparently improve predictive accuracy for OS in resected intrahepatic cholangiocarcinoma patients in comparison with TNM staging systems alone [13]. Thus, we speculated that circulating Alb/Fib ratio (AFR) and Fib/pAlb ratio (FPR), which reflected status of inflammation and nutrition, would be novel inflammatory biomarkers of prognostic prediction for postoperative stage II and III GC patients. 
We firstly compared the clinical efficacy of preoperative circulating Fib, Alb, and pAlb, either alone or pooled, for 3 years' clinical outcome in stage II and III GC patients. Our findings revealed that FPR could independently predict postoperative OS with superior accuracy compared with the other prognostic indicators and select the patients who could benefit from adjuvant chemotherapy. Additionally, a reliable prognostic nomogram based on clinical parameters and FPR could improve its predictive value of OS in the patients.

\section{RESULTS}

\section{Clinical characteristics of GC patients}

Enrolled 360 stage II and III GC patients included 261 male $(72.5 \%)$ and $99(27.5 \%)$ female and median age was 58 years (ranged from 21 to 86). During 3 years' following up, $120(33.3 \%)$ patients were confirmed dead and $240(66.7 \%)$ were alive. The postoperative histology results revealed that the majority of the patients were deep invasion (T3/T4) and lymph node metastasis (76.1\% and $62.8 \%$, respectively). There were $88(24.4 \%)$ patients with large tumor size $(>5 \mathrm{~cm})$. Almost half of them had poor differentiated and received adjuvant chemotherapy (55.8\% and $69.3 \%$, respectively). The median values of CEA, CA199, Fib, Alb, pAlb, AFR and FPR were 5.59 (0.1-100) $\mathrm{ng} / \mathrm{ml}, 51.81$ (0.9-700) U/ml, 3.31 (0.93-6.27) mg/dl, 38.79 (26.21-49.57) g/l, 214.15 (67.3-437.9) mg/l, 12.96 (5.7643.26), 17.97 (3.03-83.47), respectively. Other details of features are summarized in Table 1.

\section{The optimal thresholds for Fib, Alb, pAlb, AFR and FPR}

The optimal cut-points using X-tile program for preoperative circulating Fib, Alb, pAlb, AFR and FPR were
$3.3 \mathrm{mg} / \mathrm{dl}, 37 \mathrm{~g} / \mathrm{l}, 195.9 \mathrm{mg} / \mathrm{l}, 8.9$ and 12.1, respectively (Figure 1 and Supplementary Figure 1). According to the optimal cut-points, enrolled patients were divided into lowand high- groups. The details are shown in Table 2.

\section{The correlation of Fib, Alb, pAlb, AFR and FPR with the clinical parameters}

In order to investigate associations of these factors with tumor stage, 44 stage I GC patients were enrolled in our study. We compared the high groups and low groups for these indicators and increased Fib, FPR and deceased Alb, pAlb and AFR were positively correlated with age (more than 60 years), tumor size (larger than $5 \mathrm{~cm}$ ), tumor stage (III), depth of invasion depth (T3-T4), lymph node metastasis (N1-N3) and poor OS (all $P<0.001)$ (Table 2 and Figure 2). Compared with 30 preoperative patients, higher FPR were in the patients with recurrent GC $(P=0.001)$ (Figure 2F). Besides, no significant association was observed among alcohol, tobacco, hypertension, diabetes, tumor differentiation and adjuvant chemotherapy in two groups.

\section{The association between baseline characteristics and clinical prognosis}

Kaplan-Meier survival curve and log-rank test were performed to investigate the association between pathological data and postoperative 3-year survival time. The 3 years' OS curves according to Fib, pAlb, AFR and FPR were shown in Supplementary Figure 2. Both Kaplan-Meier curves and univariate analysis showed that sex, tobacco, alcohol, hypertension and diabetes were not significantly associated with OS $(P>0.05)$, while patients with older age $(\mathrm{HR}=1.541, P=0.018)$, worse differentiation $(\mathrm{HR}=1.890, P=0.001)$, larger tumor size $(\mathrm{HR}=2.580$, $P<0.001)$, deeper invasion $(\mathrm{HR}=6.238, P<0.001)$, higher tumor stage $(\mathrm{HR}=5.872, P<0.001), \mathrm{CEA} \quad(\mathrm{HR}=2.250$,
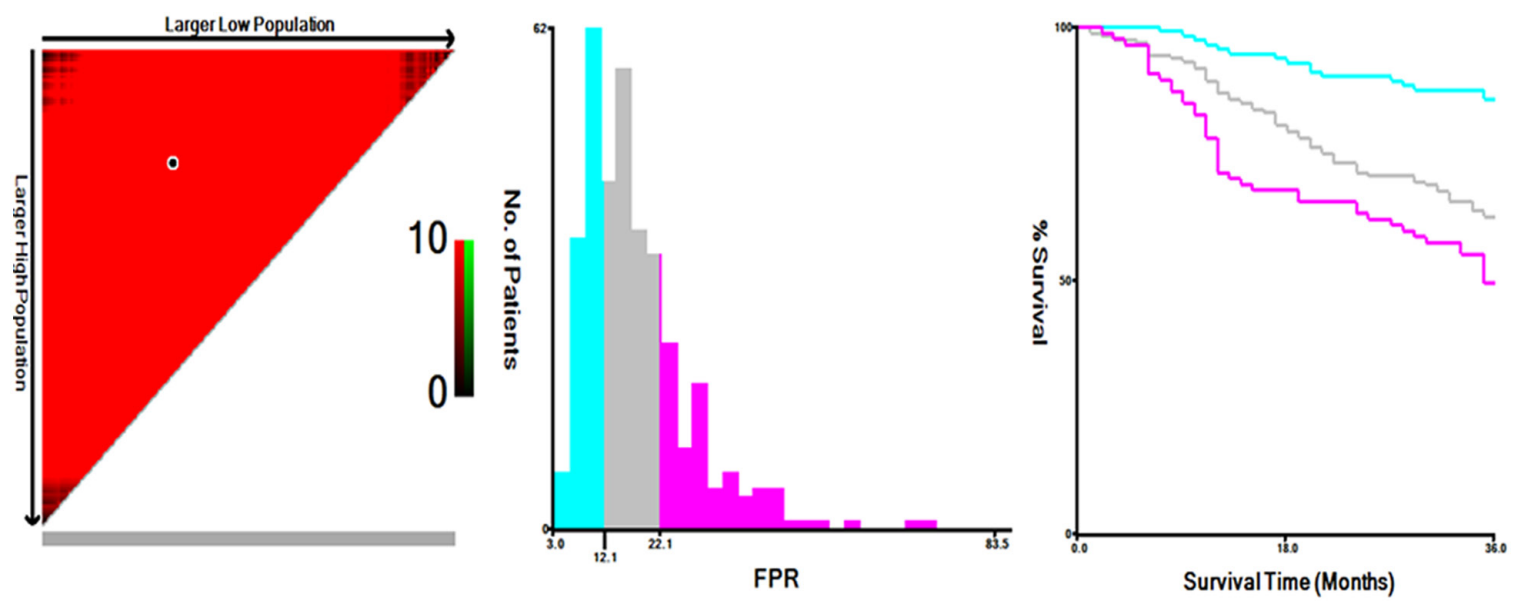

Figure 1: The optimal cut-off of preoperative circulating FPR in 360 surgically resected GC patients using X-tile software. The optimal cut-point of FPR ratio in the panels is shown on the histogram and corresponding populations are displayed on the Kaplan-Meier curve. 
Table 2: Correlation of preoperative circulating Fib, Alb, pAlb, AFR and FPR with clinicopathological characteristics in 360 GC patients

\begin{tabular}{|c|c|c|c|c|c|c|c|c|c|c|c|c|c|c|c|c|}
\hline \multirow{3}{*}{ Characteristics } & & \multicolumn{2}{|c|}{$\begin{array}{c}\text { Patients } \\
\text { grouped by }\end{array}$} & \multirow{2}{*}{$\boldsymbol{P}^{*}$} & \multicolumn{2}{|c|}{$\begin{array}{c}\text { Patients } \\
\text { grouped by }\end{array}$} & \multirow{2}{*}{$\boldsymbol{P}^{*}$} & \multicolumn{2}{|c|}{$\begin{array}{c}\text { Patients } \\
\text { grouped by }\end{array}$} & \multirow{2}{*}{$\boldsymbol{P}^{*}$} & \multirow{2}{*}{\multicolumn{2}{|c|}{$\begin{array}{c}\begin{array}{c}\text { Patients } \\
\text { grouped by }\end{array} \\
\begin{array}{c}\text { Alb level } \\
(\mathrm{n}=\mathbf{3 6 0})\end{array}\end{array}$}} & \multirow{2}{*}{$\boldsymbol{P}^{*}$} & \multirow{2}{*}{\multicolumn{2}{|c|}{$\begin{array}{c}\begin{array}{c}\text { Patients } \\
\text { grouped by }\end{array} \\
\text { pAlb level } \\
(\mathrm{n}=\mathbf{3 6 0})\end{array}$}} & \multirow{2}{*}{$\boldsymbol{P}^{*}$} \\
\hline & & \multicolumn{2}{|c|}{$\begin{array}{c}\text { FPR level } \\
(n=360)\end{array}$} & & \multicolumn{2}{|c|}{$\begin{array}{c}\text { AFR level } \\
(n=360)\end{array}$} & & \multicolumn{2}{|c|}{$\begin{array}{c}\text { Fib level } \\
(n=360)\end{array}$} & & & & & & & \\
\hline & & $\begin{array}{l}\text { FPR } \\
\text { FPR }\end{array}$ & $\begin{array}{l}12.1 \\
12.1\end{array}$ & & $\begin{array}{l}\text { AFI } \\
\text { AFI }\end{array}$ & & & & $\begin{array}{l}3.3 \\
=3.3 \\
/ d l\end{array}$ & & \multicolumn{2}{|c|}{$\begin{array}{c}\text { Alb }>37 \\
\text { Alb } \leq 37 g / l\end{array}$} & & \multicolumn{2}{|c|}{$\begin{array}{c}\text { pAlb }>195.9 \\
p A l b \leq 195.9 \\
\mathrm{mg} / \mathrm{l}\end{array}$} & \\
\hline \multirow[t]{2}{*}{ Gender } & Male & 177 & 84 & 0.732 & 204 & 57 & 0.062 & 122 & 139 & 0.463 & 179 & 82 & 0.253 & 154 & 107 & 0.049 \\
\hline & Female & 69 & 30 & & 86 & 13 & & 42 & 57 & & 74 & 25 & & 47 & 52 & \\
\hline \multirow[t]{2}{*}{ Age(years) } & $\leq 60$ & 120 & 86 & $<0.001$ & 182 & 24 & 0.015 & 70 & 136 & $<0.001$ & 162 & 44 & $<0.001$ & 127 & 79 & 0.010 \\
\hline & $>60$ & 126 & 28 & & 108 & 46 & & 94 & 60 & & 91 & 63 & & 74 & 80 & \\
\hline \multirow[t]{2}{*}{ Tobacco } & Yes & 83 & 37 & 0.810 & 90 & 30 & 0.060 & 63 & 57 & 0.061 & 78 & 42 & 0.121 & 64 & 56 & 0.499 \\
\hline & No & 163 & 77 & & 200 & 40 & & 101 & 139 & & 175 & 65 & & 137 & 103 & \\
\hline \multirow[t]{2}{*}{ Alcohol } & Yes & 55 & 27 & 0.780 & 62 & 20 & 0.198 & 41 & 41 & 0.358 & 52 & 30 & 0.122 & 46 & 36 & 0.956 \\
\hline & No & 191 & 87 & & 228 & 50 & & 123 & 155 & & 201 & 77 & & 155 & 123 & \\
\hline \multirow[t]{2}{*}{ Hypertension } & Yes & 29 & 15 & 0.712 & 35 & 9 & 0.857 & 24 & 20 & 0.201 & 29 & 15 & 0.499 & 26 & 18 & 0.642 \\
\hline & No & 217 & 99 & & 255 & 61 & & 140 & 176 & & 224 & 92 & & 175 & 141 & \\
\hline \multirow[t]{2}{*}{ Diabetes } & Yes & 13 & 4 & 0.597 & 9 & 8 & 0.003 & 12 & 5 & 0.034 & 12 & 5 & 0.977 & 6 & 11 & 0.081 \\
\hline & No & 233 & 110 & & 281 & 62 & & 152 & 191 & & 241 & 102 & & 195 & 148 & \\
\hline \multirow[t]{2}{*}{ Chemotherapy } & Yes & 164 & 85 & 0.131 & 206 & 43 & 0.118 & 109 & 140 & 0.310 & 185 & 64 & 0.012 & 143 & 106 & 0.361 \\
\hline & No & 82 & 29 & & 84 & 27 & & 55 & 56 & & 68 & 43 & & 58 & 53 & \\
\hline \multirow[t]{2}{*}{ Differentiation } & well & 111 & 48 & 0.592 & 125 & 34 & 0.408 & 71 & 88 & 0.760 & 106 & 53 & 0.182 & 90 & 69 & 0.793 \\
\hline & poor & 135 & 66 & & 165 & 36 & & 93 & 108 & & 147 & 54 & & 111 & 90 & \\
\hline Tumor stage & II & 67 & 56 & $<0.001$ & 110 & 13 & 0.002 & 40 & 83 & $<0.001$ & 100 & 23 & 0.001 & 78 & 55 & 0.048 \\
\hline & III & 179 & 58 & & 180 & 57 & & 124 & 113 & & 153 & 84 & & 123 & 54 & \\
\hline Depth of invasion & $\mathrm{T} 1-\mathrm{T} 2$ & 45 & 41 & $<0.001$ & 78 & 8 & 0.006 & 27 & 59 & 0.003 & 71 & 15 & 0.004 & 56 & 30 & 0.047 \\
\hline & T3-T4 & 201 & 73 & & 212 & 62 & & 137 & 137 & & 182 & 92 & & 145 & 129 & \\
\hline Lymph node & N0 & 83 & 51 & 0.045 & 118 & 16 & 0.006 & 52 & 82 & 0.048 & 105 & 29 & 0.010 & 81 & 53 & 0.175 \\
\hline & $\mathrm{N} 1-\mathrm{N} 3$ & 163 & 63 & & 172 & 54 & & 112 & 114 & & 148 & 78 & & 120 & 106 & \\
\hline Tumor size(cm) & $\leq 5$ & 175 & 97 & 0.004 & 232 & 40 & $<0.001$ & 112 & 160 & 0.003 & 203 & 69 & 0.001 & 169 & 103 & $<0.001$ \\
\hline & $>5$ & 71 & 17 & & 58 & 30 & & 52 & 36 & & 50 & 38 & & 32 & 56 & \\
\hline $\mathrm{CEA}(\mathrm{ng} / \mathrm{ml})$ & $\leq 5$ & 203 & 106 & 0.008 & 255 & 54 & 0.020 & 136 & 173 & 0.143 & 218 & 91 & 0.781 & 178 & 131 & 0.096 \\
\hline & $>5$ & 43 & 8 & & 35 & 16 & & 28 & 23 & & 35 & 16 & & 23 & 28 & \\
\hline CA199(U/ml) & $\leq 37$ & 201 & 102 & 0.045 & 244 & 59 & 0.823 & 134 & 169 & 0.244 & 214 & 89 & 0.818 & 175 & 129 & 0.163 \\
\hline & $>37$ & 44 & 11 & & 45 & 10 & & 29 & 26 & & 38 & 17 & & 26 & 29 & \\
\hline OS & alive & 143 & 97 & $<0.001$ & 208 & 32 & $<0.001$ & 91 & 149 & $<0.001$ & 185 & 55 & $<0.001$ & 157 & 83 & $<0.001$ \\
\hline & dead & 103 & 17 & & 38 & 38 & & 73 & 47 & & 68 & 52 & & 44 & 76 & \\
\hline
\end{tabular}


$P<0.001)$, CA199 $(\mathrm{HR}=1.932, P=0.003)$, Fib $(\mathrm{HR}=2.142$, $P<0.001)$ and FPR $(\mathrm{HR}=3.373, P<0.001)$, lower $\mathrm{Alb}$ $(\mathrm{HR}=2.140, \quad P<0.001), \quad \mathrm{pAlb} \quad(\mathrm{HR}=2.672, \quad P<0.001)$, AFR $(\mathrm{HR}=2.343, P<0.001)$, worse tumor differentiation $(\mathrm{HR}=1.890, P=0.001)$ and more lymph node metastases (HR=3.874, $P<0.001)$ were significant prognostic factors for worse OS (Table 3). Multivariate analysis showed that not only worse differentiation (adjusted $\mathrm{HR}=1.774, P=0.005$ ), larger tumor size (adjusted $\mathrm{HR}=1.930, P=0.001$ ) and more lymph node metastases (adjusted HR=2.201, $P=0.009$ ), but also lower Alb (adjusted HR=1.614, $P=0.014$ ), pAlb (adjusted $\mathrm{HR}=2.111, P<0.001$ ), AFR (adjusted $\mathrm{HR}=1.540$, $P=0.044$ ) and higher CEA (adjusted $\mathrm{HR}=1.739, P=0.013$ ), FPR (adjusted $\mathrm{HR}=2.325, P=0.002$ ) were identified as independent prognostic factors for shorter OS, but age, Fib and CA199 were not $(P>0.05)$ (Table 3$)$.

\section{Time-dependent ROC analysis}

To further evaluate the prognostic value of inflammation-based prognostic factors, time-dependent ROC analysis was performed. The result of timedependent ROC analysis presented that the lower area under the receiver operating characteristic curve (AUC) for FPR in the early period ( $<6$ months) and the higher
AUC therefore ( $>6$ months) among these prognostic indicators including Fib, Alb, pAlb, AFR, CEA and CA199 (Figure 3).

\section{FPR and clinical adjuvant chemotherapy}

We compared the prognosis of stage II and III GC patients receiving or not adjuvant chemotherapy in the subgroups stratified by FPR. Survivals of stage II and III GC patients were significantly longer in low FPR subgroup than them in high FPR subgroup $(P=0.007$ and $P=0.002$, respectively). Low level of FPR (adjusted $\mathrm{HR}=5.851,95 \% \mathrm{CI}=2.147-15.949$ ) were significantly associated with reduced survival in the III stage patients without chemotherapy comparing to the patients undergoing chemotherapy. However, no difference of survival was examined in stage II subgroups stratified by FPR and high FRP of stage III subgroup receiving or not the treatment of adjuvant chemotherapy (Table 4 and Figure 4).

\section{Prognostic nomogram for 3-year overall survival}

To predict the survival of stage II and III GC patients underwent surgical resection, prognostic nomograms
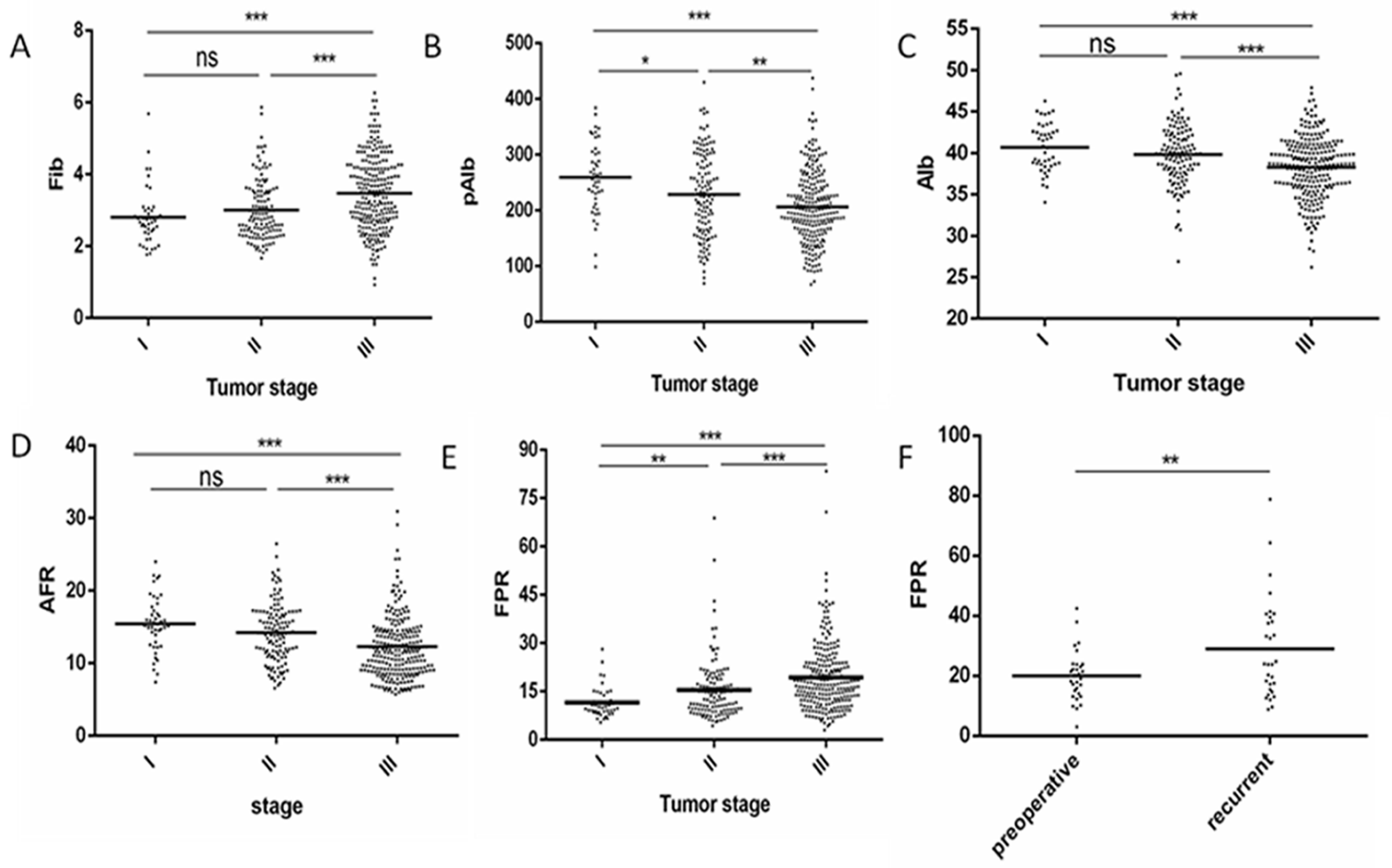

Figure 2: The relationship between tumor stage and Fib, pAlb, Alb, AFR, FPR in 360patients with GC and comparison of FPR in preoperative and recurrent 30 GC patients. (A) Fib; (B) pAlb; (C) Alb; (D) AFR; (E) FPR; (F) comparison of FPR in preoperative and recurrent patients. ${ }^{*} P<0.05,{ }^{*} P<0.01$, ${ }^{* * *} P<0.001$, ns: not significant. 
Table 3: Univariate and multivariate analyses of prognostic factors for 3 years' OS by Cox regression model

\begin{tabular}{|c|c|c|c|c|c|c|}
\hline \multirow{3}{*}{ Variables } & \multicolumn{6}{|c|}{ Overall survival } \\
\hline & \multicolumn{3}{|c|}{ Univariate analysis } & \multicolumn{3}{|c|}{ Multivariate analysis } \\
\hline & HR & $95 \%$ CI & $\boldsymbol{P}$ & HR & $(95 \%$ CI $)$ & $\boldsymbol{P}$ \\
\hline Sex (male) & 11.051 & $(0.701-1.574)$ & 0.811 & - & & - \\
\hline Age ( $>60$ years) & 1.541 & $(1.077-2.205)$ & 0.018 & 1.328 & $(0.905-1.948)$ & 0.147 \\
\hline Tobacco (yes) & 1.020 & $(0.698-1.490)$ & 0.920 & - & & - \\
\hline Alcohol (yes) & 1.167 & $(0.772-1.765)$ & 0.463 & - & & - \\
\hline Hypertension (yes) & 1.345 & $(0.815-2.220)$ & 0.247 & - & & - \\
\hline Diabetes (yes) & 1.483 & $(0.724-3.309)$ & 0.281 & - & & - \\
\hline Chemotherapy (no) & 1.493 & $(1.032-2.161)$ & 0.034 & 1.682 & $(1.136-2.488)$ & 0.009 \\
\hline Differentiation (poor) & 1.890 & $(1.289-2.770)$ & 0.001 & 1.774 & $(1.193-2.639)$ & 0.005 \\
\hline Tumor stage (III) & 5.872 & $(3.233-10.67)$ & $<0.001$ & 5.006 & $(2.712-9.241)$ & $<0.001$ \\
\hline $\begin{array}{l}\text { Depth of invasion } \\
\text { (T3-T4) }\end{array}$ & 6.238 & (2.906-13.39) & $<0.001$ & 2.293 & $(0.917-5.738)$ & 0.076 \\
\hline lymph node (N1-N3) & 3.874 & $(2.372-6.328)$ & $<0.001$ & 2.088 & $(1.202-3.626)$ & 0.009 \\
\hline Tumor size $(>5 \mathrm{~cm})$ & 2.580 & $(1.790-3.720)$ & $<0.001$ & 1.930 & $(1.326-2.808)$ & 0.001 \\
\hline $\mathrm{CEA}(>5 \mathrm{ng} / \mathrm{ml})$ & 2.250 & $(1.465-3.456)$ & $<0.001$ & 1.739 & $(1.123-2.694)$ & 0.013 \\
\hline CA199 (>37U/ml) & 1.932 & $(1.258-2.968)$ & 0.003 & 1.119 & $(0.686-1.824)$ & 0.653 \\
\hline Fib $(>3.0 \mathrm{mg} / \mathrm{dl})$ & 2.142 & $(1.484-3.091)$ & $<0.001$ & 1.463 & $(0.996-2.149)$ & 0.052 \\
\hline $\operatorname{Alb}(\leq 36.4 \mathrm{~g} / \mathrm{l})$ & 2.140 & $(1.490-3.072)$ & $<0.001$ & 1.614 & $(1.103-2.361)$ & 0.014 \\
\hline $\mathrm{pAlb}(\leq 194.1 \mathrm{mg} / \mathrm{l})$ & 2.672 & $(1.842-3.875)$ & $<0.001$ & 2.111 & $(1.437-3.100)$ & $<0.001$ \\
\hline $\operatorname{AFR}(\leq 8.9)$ & 2.343 & $(1.594-3.445)$ & $<0.001$ & 1.540 & $(1.013-2.343)$ & 0.044 \\
\hline FPR $(>12.1)$ & 3.373 & $(2.018-5.636)$ & $<0.001$ & 2.325 & $(1.372-3.940)$ & 0.002 \\
\hline
\end{tabular}

Abbreviation: HR: hazard ratio; CI: confidence interval; Fib: fibrinogen; Alb: albumin; pAlb: pre-Albumin; AFR: albumin/ fibrinogen ratio; FPR: fibrinogen/pre-Albumin ratio (FPR); CEA: carcinoembryonic antigen; HR (95\%) was adjusted by sex, age, alcohol, tobacco, hypertension, diabetes, chemotherapy, tumor size, tumor grade, tumor stage, CEA and CA199.

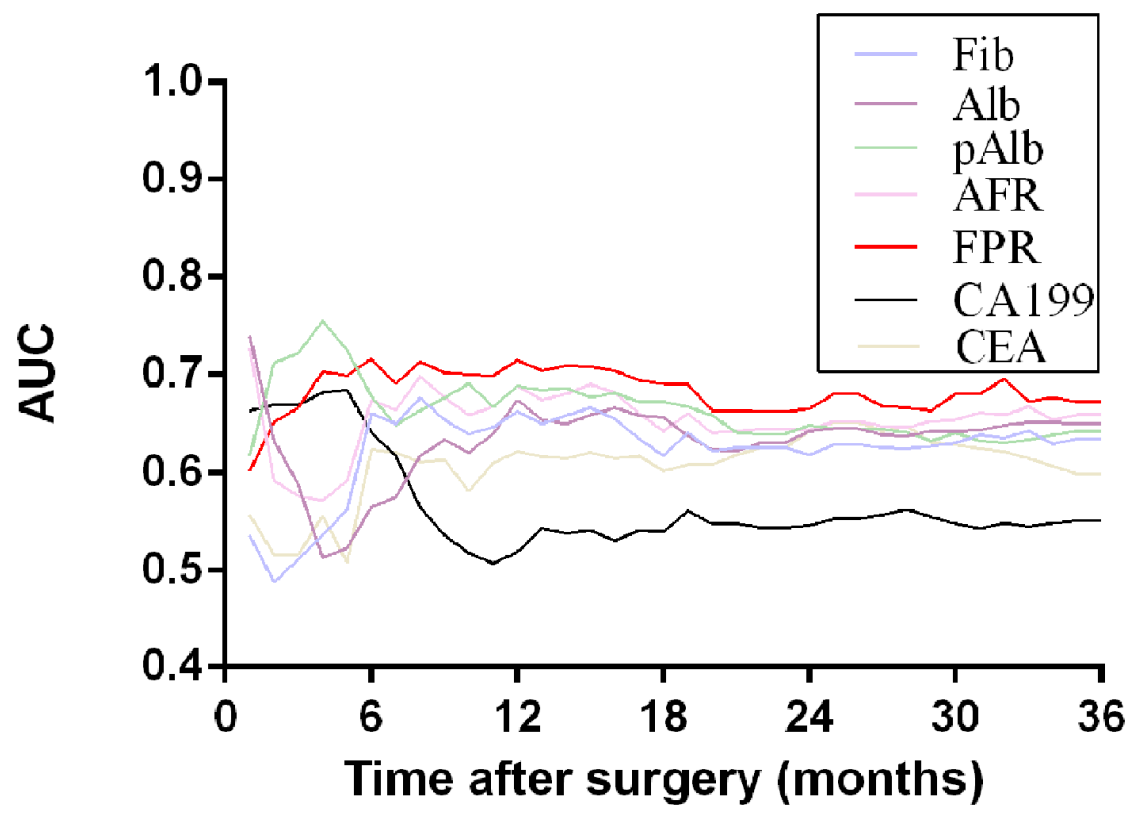

Figure 3: Time-dependent ROC analysis of preoperative circulating Fib, Alb, pAlb, AFR, FPR, CA199 and CEA for clinical outcome of $360 \mathrm{GC}$ patients. 
Table 4: Univariate and multivariate analyses of high/low FPR for chemotherapy by Cox regression model

\begin{tabular}{|c|c|c|c|c|c|c|c|}
\hline \multirow{2}{*}{ Variables } & \multirow{2}{*}{ Chemotherapy } & \multicolumn{3}{|c|}{ Univariate analysis } & \multicolumn{3}{|c|}{ Multivariate analysis } \\
\hline & & HR & $(95 \%$ CI $)$ & $\boldsymbol{P}$ & HR & $(95 \% \mathrm{CI})$ & $\boldsymbol{P}$ \\
\hline \multirow[t]{2}{*}{$\operatorname{FPR}(>12.1)$} & yes & 1 & & & - & & \\
\hline & no & 1.205 & $0.806-1.803$ & 0.363 & - & & \\
\hline \multirow[t]{2}{*}{$\operatorname{FPR}(\leq 12.1)$} & yes & 1 & & & 1 & & \\
\hline & no & 2.990 & $1.153-7.754$ & 0.024 & 5.851 & $2.147-15.949$ & 0.001 \\
\hline
\end{tabular}

Abbreviation: HR: hazard ratio; CI: confidence interval; FPR: fibrinogen/pre-Albumin ratio; HR (95\%) was adjusted by sex, age, alcohol, tobacco, hypertension, diabetes, tumor size, tumor grade, tumor stage, CEA and CA199.

were established using all the significantly independent indicators for OS (Figure 5A). The nomogram with FPR (c-index: 0.756) was more accurate than that without FPR (c-index: 0.748) in prediction of 3-year OS after initial surgery (Figure 5B).

\section{DISCUSSION}

Most of the GC patients are diagnosed in an advanced stage and the survival rates of them are relatively low, therefore, promising prognostic biomarkers that enable to identify the patients who could obviously benefit from chemotherapy and predict survival of them are crucial $[14,15]$. In this study, we found that evaluated FPR was significantly associated with T3-4 invasion, node metastasis and larger tumor size and was superior to other biomarkers to independently predict poor survival both within stage II-III, II and III subgroups; moreover, clinical outcome of III stage patients with low FPR appeared to obviously benefit from adjuvant chemotherapy in comparison with high FPR stage III patients, and the biomarker could improve the predicted efficacy of nomogram for stage II-III GC.

To date, some researchers have reported that high level of Fib, low level of Alb and pAlb were recognized as important prognostic factors influencing cancer progression $[10,11,16]$, which were consistent with our findings. Due to few patients died from the disease within 6 months after surgical resection, low AUC of FPR was observed in the early period, and the AUC was gradually increased and higher than the other biomarkers, indicating that FPR was superior to these biomarkers to apparently improve predictive efficacy of prognosis within II-III stage GC patients. In addition, it could precisely classify stage III GC patients who appeared to benefit from adjuvant chemotherapy obviously. The following causes might be accounted for our findings. Firstly, it had been shown that Fib acts as a bridging molecule between GC cells and surrounding microenvironment. Adams et al. demonstrated that it as a ligand for integrin and intercellular adhesion molecule presented on malignant cell surface to mediate coagulation, inflammation and immunity [17]. Secondly, Fib enhanced b3-integrin-mediated vascular endothelial adhesion of platelets to tumor cells, and platelets in turn promoted more Fib to aggregate around tumor cells by forming thrombin. They facilitated each other to protect tumor cells escaping from cytotoxicity of nature killer cells [18]. Palumbo et al. reported that lymphatic metastasis, but not primary tumor growth or angiogenesis, was diminished in fibrinogen-deficient mice, suggesting that Fib was a critical determinant of the metastatic potential by impeding elimination of tumor cell by natural killer cell $[19,20]$. Thirdly, serum Alb was one of the most widely used markers for reflecting nutritional status and hypoproteinmia was reported as a crucial parameter of malnutrition and directly influenced prognosis of GC; low levels of Alb and pAlb levels have an impact on determinant of immune responses and malnutrition, which could impair immune system defending against GC $[21,22]$.

This study, to best of our knowledge, is the first to investigate prognostic role of AFR and FPR in GC. Certain advantages and limitations should address to explain our results. To some extent, hypoalbuminemia has been considered to be an inflammatory indicator in GC, rather than only a factor indicates malnutrition [4]. Therefore, single clinical blood marker is limited and unstable to predict prognosis of GC. Our results did firstly find that FPR is a superior prognostic indicator compared to Fib, Alb, or pAlb alone, for they reflected not only inflammation but also nutritional status of GC patients. Besides, circulating Fib to pAlb ratio will expand prognostic range to avoid a single indicator causing false negative or positive results. Finally, we figured out the 
visual nomogram based on FPR, which could predict prognosis in postoperative stage II and III GC patients within 3 years more accurately. Therefore, preoperative calculation of FPR may help to predict 3 years' OS in surgical GC patients. However, we acknowledge some potential limitations in our study. Since the results of our study may be affected by a short follow-up period, singleinstitution design and a small sample size retrospective study, larger patients with $\mathrm{GC}$ are required to confirm our findings.

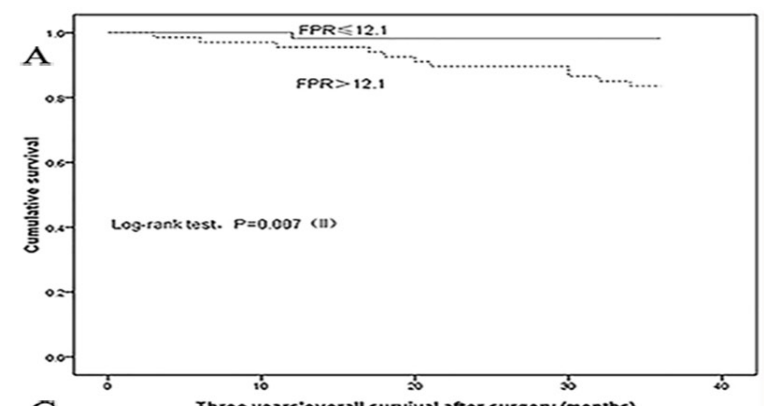

C

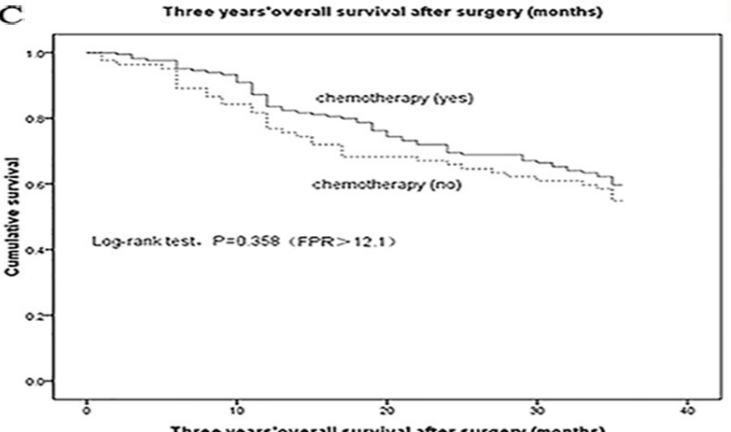

E

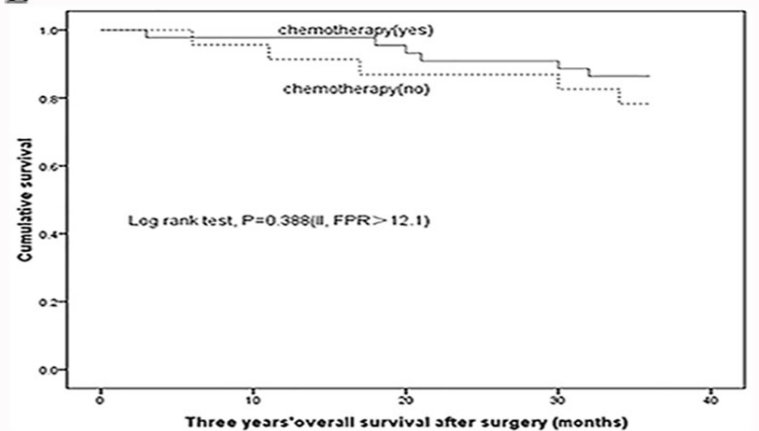

G

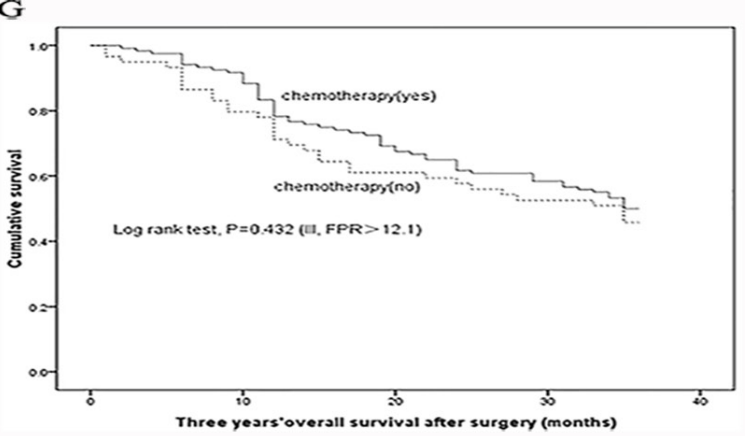

B

D
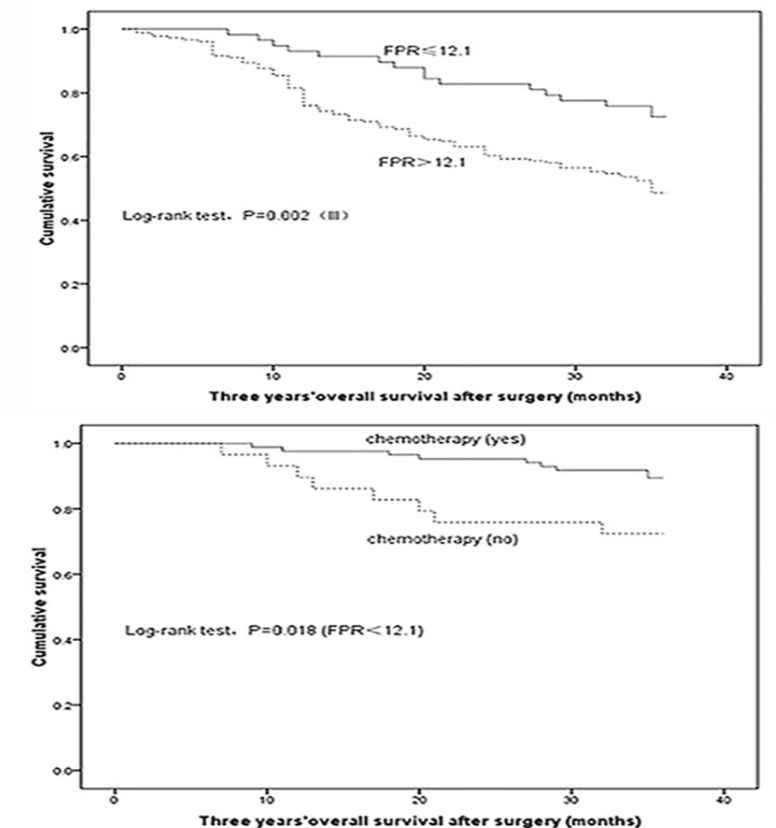

F

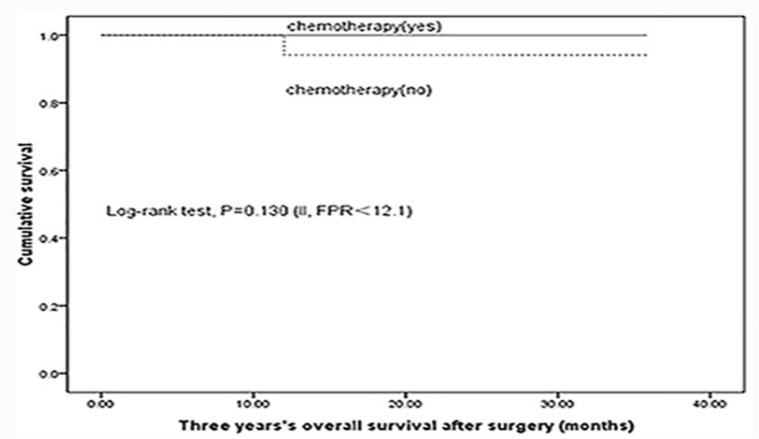

H

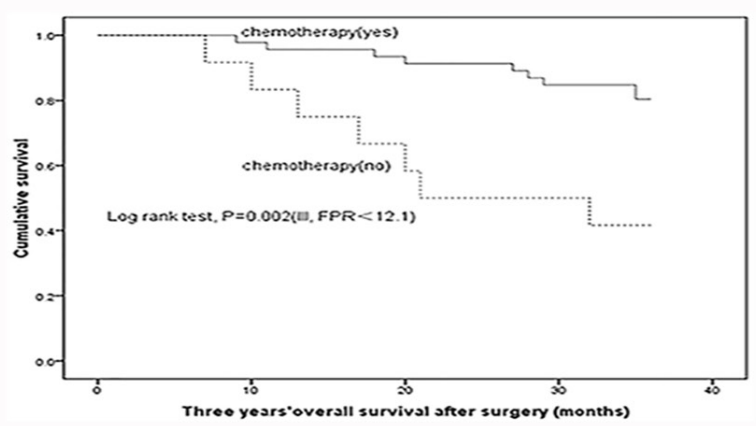

Figure 4: Kaplan-Meier curves analysis in each subgroup. (A) stage II patient; (B) stage III patient; (C) high FPR subgroup; (D) low FPR subgroup; (E) FPR-high stage II subgroup; (F) FPR-low stage II subgroup; (G) FPR-high stage III subgroup; (H) FPR-low stage III subgroup. 
A

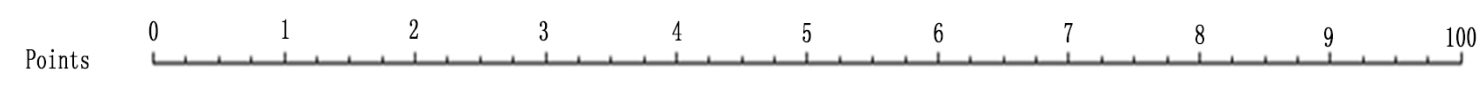

Age $\quad>60$

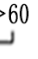

Stage II

Chemotherapy

Differentiation $\stackrel{\text { Poor }}{\longrightarrow}$

Mel1

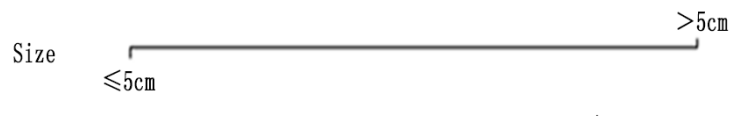

$\mathrm{CEA} \leqslant 5 \mathrm{ng} / \mathrm{ml}>5 \mathrm{ng} / \mathrm{ml}$

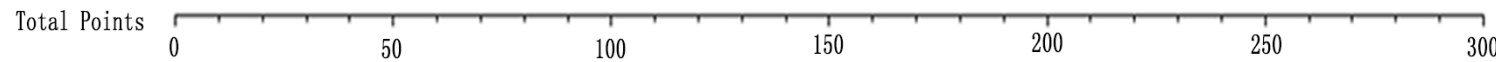

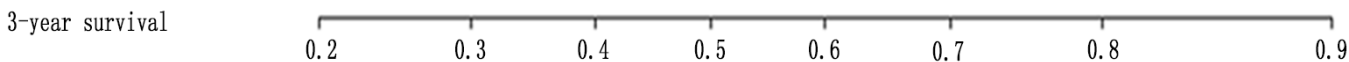

B

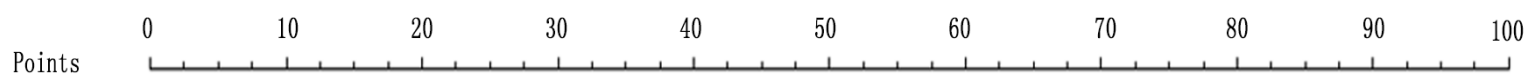

III

Stage

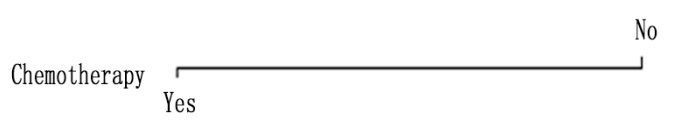

Differentiation Pell Poor
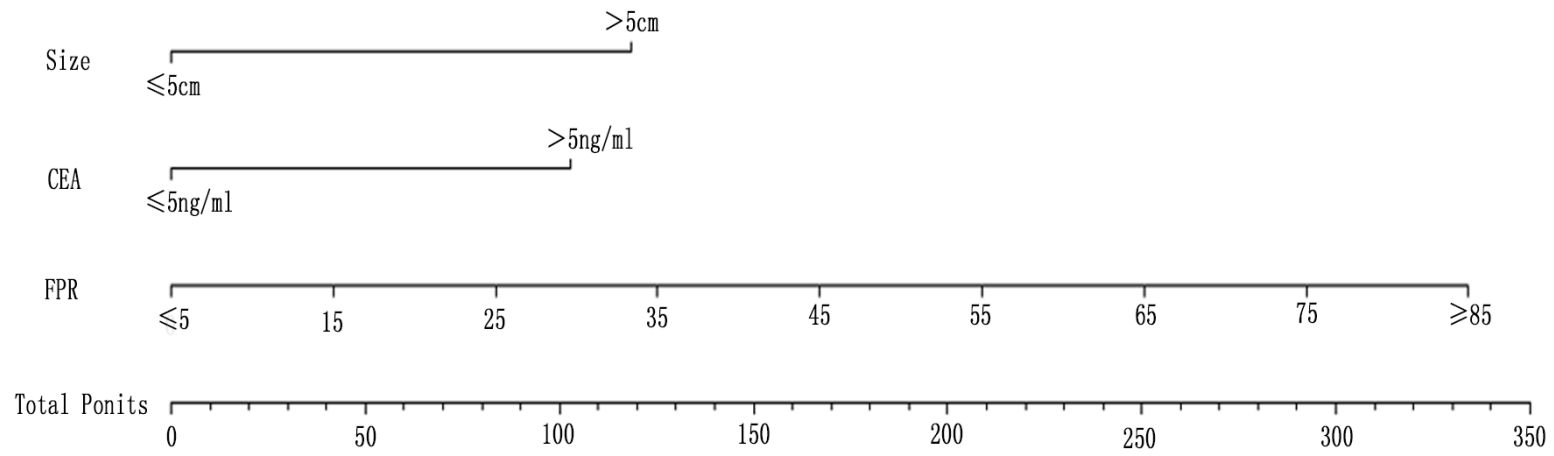

3-year survival

\begin{tabular}{llllllll|l}
\hline & & & & & & & & \\
0.2 & 0.3 & 0.4 & 0.5 & 0.6 & 0.7 & 0.8 & 0.9 & 0.95
\end{tabular}

Figure 5: Postoperative nomogram estimated by clinical characteristics and FPR for 3-years' OS in 360 GC patients. (A) without FPR; (B) with FPR. 


\section{MATERIALS AND METHODS}

\section{Patients}

Three hundred and sixty newly diagnosed stage II and III GC patients were included in this retrospective study and all of them underwent surgical resection from June 2011 to December 2013 at the Second Affiliated Hospital of Nanchang University. The diagnostic criteria for $\mathrm{GC}$ were according to the seventh edition of tumor-nodes-metastasis (TNM) staging system [23]. In the contrary, patients were excluded as follows: 1) all patients had infection or inflammation-related diseases for nearly one month, autoimmune diseases and blood diseases; 2) patients who received preoperative antiinflammatory or anticancer therapy; 3) patients with abnormal liver function, mixed cancers and distant metastasis; 4) absent data regarding preoperative prognostic biomarkers. The study was approved by the Ethical Committee of the Second Affiliated Hospital of Nanchang University.

\section{Data collection and laboratory detection}

Through patients' medical record and pathological report, we gathered data including age, sex, personal history and postoperative clinical and pathological characteristics. All peripheral blood samples were collected at 7:30 to 9:30 am within three days before surgical operation. Plasma and serum samples were centrifuged at $3000 \mathrm{~g}$ for $5 \mathrm{~min}$. Plasma Fib concentration were detected using Clauss method by SYSMEX CA7000 machine (Sysmex, Tokyo, Japan), its inter- and intra-batch coefficient of variation (CV) of the kit were $4.41 \%$ and $3.66 \%$, respectively. Bromocresol green, immune turbidimetric and electrochemiluminescence methods were used to detect serum Alb, pAlb, CA199 and CEA using OLYMPUS AU5400 machine(Beckman Coulter, Tokyo, Japan) and COBAS e411 (Roche, Basel, Switzerland), respectively. The inter- and intra-batch CVs of the kits were $3.17 \%$ and $1.83 \%, 3.09 \%$ and $2.76 \%$, $3.32 \%$ and $3.25 \%, 3.48 \%$ and $3.26 \%$, respectively. In each batch, blinded quality controlled samples were included, and all the markers were measured triplicate in all plasma samples.

\section{Follow-up}

After surgery, all stage II and III GC patients were followed up regularly until December $31^{\text {th }} 2016$ (every 6 months up to 3th year by telephone). For drop-out patients, the date was obtained by outpatient medical records. Overall survival (OS) was measured from the date of operation to death from any causes or last following-up.

\section{Statistical analysis}

The optimal cut-off levels of prognostic factors were determined by X-tile software. Chi-square test and Mann-Whitney $U$ or Kruskal-Wallis test were used to analyze categorical variables and continuous variables with non-normal distributions, respectively. Kaplan-Meier survival curve was applied for survival analysis and the differences in survival rate were performed by the logrank test. Hazards ratio (HR) for death was estimated with a Cox proportional hazards model. Prognostic nomogram, Harrell's concordance index (c-index) and Time-dependent ROC were analyzed by the rms and survivalROC packages, respectively. Statistical analyses were carried out using SPSS 19.0 software (IBM Corp, Armonk, NY, USA) and R 3.0.3 software (Institute for Statistics and Mathematics, Vienna, Austria). $P<0.05$ was indicated statistically difference.

\section{CONCLUSIONS}

It is worth emphasizing that preoperative FPR is more compelling in predicting three years' OS in surgical stage II and III GC than Fib or pAlb alone and adjuvant chemotherapy might be more beneficial to FPR-low stage III GC patients. Due to survival heterogeneity of GC patients, larger cohort prospective studies, especially prospective multicenter clinical trials, are warranted to further validate the results.

\section{ACKNOWLEDGMENTS AND GRANT SUPPORT}

This report was supported by the National Natural Science Foundation of China (NO.81360083 and NO.81560033), Natural Science Youth Foundation of Jiangxi Province (No. 20171BAB215054), and Key Technology Research and Development Program of Jiangxi Province (No.20071BBG70049).

\section{CONFLICTS OF INTEREST}

All authors declare no conflicts of interest, financial in the publication of the study.

\section{REFERENCES}

1. Ajani JA, Bentrem DJ, Besh S, D'Amico TA, Das P, Denlinger C, Fakih MG, Fuchs CS, Gerdes H, Glasgow RE, Hayman JA, Hofstetter WL, Ilson DH, et al. Gastric cancer, version 2. 2013: featured updates to the NCCN Guidelines. J Natl Compr Canc Netw. 2013; 11:531-546.

2. Chen LT, Oh DY, Ryu MH, Yeh KH, Yeo W, Carlesi R, Cheng R, Kim J, Orlando M, Kang YK. Anti-angiogenic 
Therapy in Patients with Advanced Gastric and Gastroesophageal Junction Cancer: A Systematic Review. Cancer Res Treat. 2017; [Epub ahead of print].

3. Balkwill F, Mantovani A. Inflammation and cancer: back to Virchow? Lancet. 2001; 357:539-545.

4. Sachlova M, Majek O, Tucek S. Prognostic value of scores based on malnutrition or systemic inflammatory response in patients with metastatic or recurrent gastric cancer. Nutr Cancer. 2014; 66:1362-1370.

5. Seo KW, Yoon KY. [Nutritional assessment and perioperative nutritional support in gastric cancer patients]. [Article in Korean]. Korean J Gastroenterol. 2013; 61:186-190.

6. Dias Rodrigues V, Barroso de Pinho N, Abdelhay E, Viola JP, Correia MI, Brum Martucci R. Nutrition and ImmuneModulatory Intervention in Surgical Patients With Gastric Cancer. Nutr Clin Pract. 2017; 32:122-129.

7. Kim YI, Kim SY, Kim JH, Lee JH, Kim YW, Ryu KW, Park JH, Choi IJ. Long-Term Low-Dose Aspirin Use Reduces Gastric Cancer Incidence: A Nationwide Cohort Study. Cancer Res Treat. 2016; 48:798-805.

8. Yu W, Wang Y, Shen B. An elevated preoperative plasma fibrinogen level is associated with poor overall survival in Chinese gastric cancer patients. Cancer Epidemiol. 2016; 42:39-45.

9. Yu X, Hu F, Yao Q, Li C, Zhang H, Xue Y. Serum fibrinogen levels are positively correlated with advanced tumor stage and poor survival in patients with gastric cancer undergoing gastrectomy: a large cohort retrospective study. BMC Cancer. 2016; 16:480.

10. Suzuki T, Shimada H, Nanami T, Oshima Y, Yajima S, Ito M, Washizawa N, Kaneko H. Hyperfibrinogenemia is associated with inflammatory mediators and poor prognosis in patients with gastric cancer. Surg Today. 2016; 46:1394-1401.

11. Han WX, Chen ZM, Wei ZJ, Xu AM. Preoperative prealbumin predicts prognosis of patients after gastrectomy for adenocarcinoma of esophagogastric junction. World J Surg Oncol. 2016; 14:279.

12. Kang SC, Kim HI, Kim MG. Low Serum Albumin Level, Male Sex, and Total Gastrectomy Are Risk Factors of Severe Postoperative Complications in Elderly Gastric Cancer Patients. J Gastric Cancer. 2016; 16:43-50.
13. Jing CY, Fu YP, Shen HJ, Zheng SS, Lin JJ, Yi Y, Huang JL, Xu X, Zhang J, Zhou J, Fan J, Ren ZG, Qiu SJ, Zhang $\mathrm{BH}$. Albumin to gamma-glutamyltransferase ratio as a prognostic indicator in intrahepatic cholangiocarcinoma after curative resection. Oncotarget. 2017; 8:13293-13303. http://doi.org/10.18632/oncotarget. 14530.

14. Wan J, Chao L, Lee AC, Chen Q. Higher Expression of ERCC1 May Be Associated with Resistance to Adjuvant Platinum-Based Chemotherapy in Gastric Cancer. Cancer Invest. 2017; 35:85-91.

15. Wang S, Yuan L. Predictive biomarkers for targeted and cytotoxic agents in gastric cancer for personalized medicine. Biosci Trends. 2016; 10:171-180.

16. Liu BZ, Tao L, Chen YZ, Li XZ, Dong YL, Ma YJ, Li SG, Li F, Zhang WJ. Preoperative Body Mass Index, Blood Albumin and Triglycerides Predict Survival for Patients with Gastric Cancer. PLoS One. 2016; 11:e0157401.

17. Adams RA, Schachtrup C, Davalos D, Tsigelny I, Akassoglou K. Fibrinogen signal transduction as a mediator and therapeutic target in inflammation: lessons from multiple sclerosis. Curr Med Chem. 2007; 14:2925-2936.

18. Zheng S, Shen J, Jiao Y, Liu Y, Zhang C, Wei M, Hao S, Zeng X. Platelets and fibrinogen facilitate each other in protecting tumor cells from natural killer cytotoxicity. Cancer Sci. 2009; 100:859-865.

19. Palumbo JS, Kombrinck KW, Drew AF, Grimes TS, Kiser JH, Degen JL, Bugge TH. Fibrinogen is an important determinant of the metastatic potential of circulating tumor cells. Blood. 2000; 96:3302-3309.

20. Palumbo JS, Talmage KE, Massari JV, La Jeunesse CM, Flick MJ, Kombrinck KW, Jirouskova M, Degen JL. Platelets and fibrin(ogen) increase metastatic potential by impeding natural killer cell-mediated elimination of tumor cells. Blood. 2005; 105:178-185.

21. Sun KY, Xu JB, Chen SL, Yuan YJ, Wu H, Peng JJ, Chen CQ, Guo P, Hao YT, He YL. Novel immunological and nutritional-based prognostic index for gastric cancer. World J Gastroenterol. 2015; 21:5961-5971.

22. Li B, Liu HY, Guo SH, Sun P, Gong FM, Jia BQ. Impact of early postoperative enteral nutrition on clinical outcomes in patients with gastric cancer. Genet Mol Res. 2015; 14:7136-7141.

23. Washington K. 7th edition of the AJCC cancer staging manual: stomach. Ann Surg Oncol. 2010; 17:3077-3079. 